\title{
28 Research Square \\ Correlation of Diabetes and Cancers: A Survey of Hospitalized Patients in the United State, 2005-2015
}

\author{
Alireza Mirahmadizadeh \\ Shiraz University of Medical Sciences \\ Mohammad Hossein Sharifi \\ Shiraz University of Medical Sciences \\ Mohammad Aryaie \\ Shiraz University of Medical Sciences
}

\section{Zahra Gheibi}

Shiraz University of Medical Sciences

\section{Alireza Rezvani}

Shiraz University of Medical Sciences

\section{Shahryar Zeighami}

Shiraz University of Medical Sciences

\section{Alireza Heiran}

Shiraz University of Medical Sciences

\author{
Ali Seifi ( $\nabla$ seifi@uthscsa.edu ) \\ University of Texas Health Science Center at San Antonio
}

\section{Research Article}

Keywords: Correlation, Diabetes, Cancer, HCUP-NIS

Posted Date: October 21st, 2021

DOI: https://doi.org/10.21203/rs.3.rs-963608/v1

License: (c) This work is licensed under a Creative Commons Attribution 4.0 International License. Read Full License 


\section{Abstract}

\section{Background}

In recent decades, there is a growing body of literature that recognizes the relationship between diabetes and cancers. However, there is limited and contradictory evidence regarding whether diabetes is associated with an increased or decreased risk of some cancers.

\section{Method}

In this survey, data from 44,262,443 patients aged $\geq 50$ years from 2005 to 2015 were obtained from the Healthcare Cost and Utilization Project-Nationwide Inpatient Sample (HCUP-NIS) database. Univariate analysis and multivariate logistic regression between diabetes and 33 selected cancers among hospitalized patients were calculated from data extracted from the database.

\section{Results}

This study revealed that out of $44,262,443$ discharges, $13,048,961$ patients had diabetes for a prevalence of $29.48 \%$, and $11,752,871$ cases of 33 different cancers existed among 9,103,889 patients. Data revealed that the proportion of patients hospitalized with diabetes increased from $25.79 \%$ to $32.31 \%$ in uncomplicated diabetes (mean age: $70.11 \pm 11.07$ years) and from $4.47 \%$ to $7.14 \%$ in complicated diabetes (mean age: $68.71 \pm 10.72$ years). The univariate analysis and multivariate logistic regression analysis revealed that diabetes, including uncomplicated and complicated, had a protective role for 33 selected cancers as the $1^{\text {st }}-30^{\text {th }}$ diagnosis except for pancreatic cancer (OR $1.415,95 \%$ Cl: $\left.1.40-1.43\right)$, and liver and intrahepatic cancer (OR 1.199, 95\% Cl: 1.184-1.213).

\section{Conclusion}

This study presents new information on the likelihood of a protective role of diabetes in certain cancers using a large amount of individual data. Continued efforts and research are needed to provide detailed and probable biological mechanisms linking diabetes and the development and progression of cancer.

\section{Introduction}

In recent decades, there is a growing body of literature that recognizes the relationship between diabetes and cancer. Diabetes and cancer are diseases that are both rising in prevalence and have a deleterious effect on global health. The Agency for Healthcare Research and Quality estimates that the direct medical costs for cancer (in 2015) and diabetes (in 2017) in the US were $\$ 80.2$ billion and $\$ 327$ billion, respectively ${ }^{1,2}$. There is limited and contradictory evidence that diabetes is associated with an increased risk of some cancers while decreasing the risk of other cancers ${ }^{3-6}$. Nonetheless, while early evidence revealed the links between diabetes and cancer, new prospective research has found no strong evidence to support an association between diabetes and overall cancer risk or site-specific cancer risk ${ }^{4}$. Possible common risk factors between diabetes and cancer risk are still not well understood ${ }^{7}$. In addition, the risk factors of many cancers are not well defined. Evidence indicates that there are complex interactions between non-modifiable factors such as age and genetic susceptibility and modifiable factors such as diet and physical activity.

Although there is an unclear association between diabetes and cancer, evidence has shown that diabetes, without decreasing mortality rate, is positively associated with the risk of some cancers (liver, pancreas, breast, endometrium, kidney, colon, and rectum). Diabetes is also negatively associated with the risk of non-aggressive forms of prostate cancer $^{8}$. Some evidence suggests that anti-hyperglycemic medications such as metformin may have a protective effect on the progression of cancer and may even play a role in the treatment of certain cancers ${ }^{9}$. Conversely, some research has 
shown that high doses of insulin and pioglitazone ( $>24$ months and $>28,000 \mathrm{mg}$ cumulative dose) can contribute to increased risk of certain cancers ${ }^{9}$. Anti-hyperglycemic medications have been suggested to affect cancer risk via several direct and indirect mechanisms involving serum insulin levels, growth factor, chronic inflammation, estrogen, testosterone, and weight loss, among others ${ }^{8-12}$. In addition, the findings of the cohort study by Dankner et al showed that poor glycemic control seems to be only weakly correlated with cancer risk among diabetes patients. ${ }^{13}$. Despite some previous clinical evidence demonstrating longer survival time in diabetic patients with metastatic lung cancer,this improvement in survival is likely related to the protective effect of microangiopathic complications of diabetes from progression of metastatic lesions ${ }^{14}$. In summary, there is currently no agreed-upon mechanism that explains the link between diabetes and cancer risks ${ }^{4}$.

Evidence supports a causal connection between lifestyle behavior, diabetes and cancer ${ }^{15,16}$. Studies have shown that some risk factors including obesity, sedentary lifestyle, and unhealthy diet can influence both diabetes and certain cancers. After the diagnosis of diabetes is made, particularly accompanied by cardiovascular disease, lifestyle of the patient including diet, physical activity, sleep behavior may change through consultation with health care providers ${ }^{17,18}$. As a consequence, individual health habits and physiology of the body can be influenced, and cancer risk factors and progression can be affected, particularly at specific cancer sites. Furthermore, differences in the average age of diabetes diagnosis versus the average age of cancer diagnosis may contribute to the conflicting evidence regarding the association of diabetes and cancer. Over time, the age of diagnosis of diabetes has declined. The mean age of diagnosis of diabetes was 47.9 years of age, with $89.1 \%$ of participants diagnosed at age 30 or older ${ }^{19}$. However, half of all cancers are diagnosed after 65 years of age ${ }^{20}$. It is possible that improvements in the lifestyle of diabetes patients in middle age, which reduced common risk factors for certain cancers, have affected the prevalence of some cancers.

The report of the American Diabetes Association and the American Cancer Society on the relationship between diabetes and certain cancers was published in December 2009 and addressed some unanswered questions regarding these relationships ${ }^{3}$. This research might help answer questions regarding the impact of diabetes treatment on cancer. In addition, the current study might help to develop a hypothesis that diabetes could be associated with increased cancer risk.

\section{Methods}

In this survey, data from 44,262,443 patients aged 50 years and older from 2005 to Oct. 2015 were obtained from the Healthcare Cost and Utilization Project-Nationwide Inpatient Sample (HCUP-NIS) database. The HCUP-NIS represents approximately $20 \%$ of all hospitalizations across the United States and is anonymized and de-identified. The database is based on every discharge and includes clinical variables on all diagnoses and procedures. It is considered the most accurate and precise database on inpatient care and outcomes in the United States. Based on nature of this study, the informed consent was waived. Furthermore, all methods were performed in accordance with relevant guidelines and regulations.

Only patients aged 50 years and older were included for three reasons: to exclude all women who were admitted for delivery, to go beyond the average age of onset of diabetes, and to include subjects with higher risk of cancer due to age group. We grouped all diabetes cases into either uncomplicated or complicated. Also, based on International Classification of Disease, 9th Revision, Clinical Modification (ICD-9-CM), selected cancers were included in analysis as the principal (1st) diagnosis or as a subsequent $\left(2^{\text {nd }}-30^{\text {th }}\right)$ diagnosis.

Demographic information including age, gender, and race (White, Black, Hispanic, Asian or Pacific islanders, Native American, or other) was included. Other variables were also considered such as alcohol consumption, cigarette smoking, obesity, insurance type, hospital location, disease severity at admission, risk of dying, and in-hospital mortality. More 
information on HCUP-NIS is available at https://www.hcup-us.ahrq.gov/nisoverview.jsp. The Institutional Review Board of University of Texas Health at San Antonio exempted this analysis from full review.

\section{Statistical analysis}

In descriptive analysis, we showed the trend of both complicated and uncomplicated diabetes and prevalence of selected cancers. Frequency of diabetes within demographic variables and some HCUP-NIS characteristics were also analyzed. Analysis occurred in two steps: in the first step, we conducted 297 univariate analyses between diabetes (uncomplicated, complicated and both uncomplicated and complicated) and 33 selected cancers in every order of diagnosis $\left(1^{\mathrm{st}}, 2^{\text {nd }}-30^{\text {th }}\right.$, and all or $1^{\text {st }}-30^{\text {th }}$ ) present at admission or during hospitalization (Nine univariate analyses for each cancer were done). Because we analyzed cross-sectional data, we used prevalence ratio as a proxy for relative risk in order to estimate the level of association. In the second step, we utilized 297 multivariate logistic regressions to control for probable confounders (Nine multivariate logistic regressions for each cancer). Considered confounding factors were age, sex, race, obesity, smoking and alcohol consumption. The results of both univariate analysis and multivariate logistic regression have been shown in supplements 1 and 2, respectively. All analyses were carried out using Stata version 12.0 software (Stata, College Station, TX, USA).

\section{Results}

During the study period, we reviewed $44,262,443$ discharges with $13,048,961$ cases of diabetes for a prevalence of $29.48 \%$. The subjects were mainly female (53.95\%), with a mean age of 70.37 years old, mainly white (75.38\%), and overwhelmingly in an urban hospital location (86.19\%). The highest prevalence of diabetes among hospitalized patients were within the age groups of 60-69 years-old (25.02\%) and $>70$ years-old (51.72\%). Further demographic characteristics of the survey is provided in Table1. 
Table 1

Prevalence of diabetes based on demographic characteristics among hospitalized patients $\geq 50$ years in the United States, 2005-15

\begin{tabular}{|c|c|c|c|c|c|c|c|}
\hline \multicolumn{2}{|c|}{ Demographic characteristics } & \multicolumn{2}{|l|}{ Population } & \multicolumn{4}{|c|}{ Prevalence of diabetes } \\
\hline & & \multirow[t]{2}{*}{ No. } & \multirow[t]{2}{*}{$\%$} & \multicolumn{2}{|c|}{ Uncomplicated } & \multicolumn{2}{|c|}{ Complicated } \\
\hline & & & & $\%$ & P.Value & $\%$ & P.Value \\
\hline \multirow[t]{2}{*}{ Sex } & Female & $23,877,919$ & 53.95 & 23.43 & \multirow[t]{2}{*}{$<0.001$} & 5.07 & \multirow[t]{2}{*}{$<0.001$} \\
\hline & Male & $20,384,524$ & 46.05 & 24.55 & & 6.06 & \\
\hline \multirow[t]{3}{*}{ Age group } & $50-59$ & $10,298,612$ & 23.26 & 21.03 & \multirow[t]{3}{*}{$<0.001$} & 5.49 & \multirow[t]{3}{*}{$<0.001$} \\
\hline & $60-69$ & $11,077,691$ & 25.02 & 26.63 & & 6.65 & \\
\hline & $\geq 70$ & $22,898,859$ & 51.72 & 23.96 & & 5.00 & \\
\hline \multirow[t]{6}{*}{ Race } & White & $28,592,150$ & 75.38 & 22.03 & \multirow[t]{6}{*}{$<0.001$} & 4.80 & \multirow[t]{6}{*}{$<0.001$} \\
\hline & Black & $4,616,599$ & 12.17 & 30.64 & & 8.25 & \\
\hline & Hispanic & $2,822,733$ & 7.44 & 32.60 & & 9.35 & \\
\hline & Asian or Pacific Islander & 754,376 & 1.99 & 29.32 & & 8.10 & \\
\hline & Native American & 205,842 & 0.54 & 30.97 & & 9.03 & \\
\hline & Other & 938,667 & 2.47 & 27.88 & & 5.73 & \\
\hline \multirow[t]{4}{*}{ Region of hospital } & Northeast & $8,707,862$ & 19.67 & 23.47 & \multirow[t]{4}{*}{$<0.001$} & 4.80 & \multirow[t]{4}{*}{$<0.001$} \\
\hline & Midwest & $10,371,979$ & 23.43 & 24.07 & & 5.56 & \\
\hline & South & $17,260,153$ & 38.98 & 25.24 & & 5.20 & \\
\hline & West & $7,935,168$ & 17.92 & 21.48 & & 6.98 & \\
\hline \multirow[t]{2}{*}{ Hospital* location } & Rural & $4,054,695$ & 13.81 & 23.83 & \multirow[t]{2}{*}{$<0.001$} & 4.36 & \multirow[t]{2}{*}{$<0.001$} \\
\hline & Urban & $25,300,410$ & 86.19 & 23.21 & & 5.18 & \\
\hline \multirow[t]{6}{*}{ Expected primary payer } & Medicare & $29,317,350$ & 66.33 & 25.04 & \multirow[t]{6}{*}{$<0.001$} & 5.99 & \multirow[t]{6}{*}{$<0.001$} \\
\hline & Medicaid & $2,878,142$ & 6.51 & 26.90 & & 6.80 & \\
\hline & Private including $\mathrm{HMO}^{\star * *}$ & $9,614,380$ & 21.75 & 20.33 & & 4.09 & \\
\hline & Self-pay & $1,177,701$ & 2.66 & 20.64 & & 4.03 & \\
\hline & No charge & 140,700 & 0.32 & 20.89 & & 3.93 & \\
\hline & Other & $1,071,665$ & 2.42 & 22.47 & & 4.23 & \\
\hline
\end{tabular}

Figure 1 illustrates the overall increasing trend of hospitalized diabetic patients in the United States from 2005-2015. The data showed an increase in the proportion of patients hospitalized with diabetes from $25.79-32.31 \%$ in uncomplicated diabetes and from 4.47-7.14\% in complicated diabetes between 2005 and 2015.

The prevalence of 33 selected cancers (11,752,871 cases) among 44,404,065 hospitalized patients $\geq 50$ years old during the study period (2005-2015) is detailed in Table 2. Review of the analysis revealed that the average prevalence of all reported cancers increased compared to the baseline year of 2005. The result of an 11-year average showed that the 
cancers with the highest prevalence were breast cancer (32.3\%), prostate cancer (29.5\%), lung plus bronchus cancer (26.5\%), and colon cancer (21.4\%). 
Table 2

Prevalence of selected cancers (per 1,000) among hospitalized patients $\geq 50$ years in the United States, 2005-15

\begin{tabular}{|c|c|c|c|c|c|c|c|c|c|c|c|c|}
\hline \multirow[t]{2}{*}{ Cancer } & \multicolumn{11}{|l|}{ Year } & \multirow{2}{*}{$\begin{array}{l}\text { 11-year } \\
\text { Average }\end{array}$} \\
\hline & 2005 & 2006 & 2007 & 2008 & 2009 & 2010 & 2011 & 2012 & 2013 & 2014 & 2015 & \\
\hline $\begin{array}{l}\text { Head and } \\
\text { neck }\end{array}$ & 5.4 & 5.4 & 5.7 & 5.8 & 6.4 & 6.8 & 6.3 & 6.7 & 6.8 & 6.9 & 6.8 & 6.3 \\
\hline Esophagus & 2.3 & 2.2 & 2.4 & 2.3 & 2.6 & 2.6 & 2.6 & 2.6 & 2.7 & 2.7 & 2.7 & 2.5 \\
\hline Stomach & 2.7 & 2.5 & 2.8 & 2.7 & 2.7 & 2.9 & 2.8 & 2.9 & 2.9 & 2.9 & 2.8 & 2.8 \\
\hline Colon & 21.3 & 20.8 & 21.4 & 20.9 & 21.9 & 21.3 & 22.2 & 21.9 & 21.7 & 21.5 & 20.8 & 21.4 \\
\hline $\begin{array}{l}\text { Rectum and } \\
\text { anus }\end{array}$ & 5.1 & 4.9 & 5.4 & 5.2 & 5.5 & 5.5 & 5.7 & 5.7 & 5.8 & 6.2 & 6.1 & 5.6 \\
\hline $\begin{array}{l}\text { Liver, } \\
\text { intrahepatic }\end{array}$ & 2 & 2 & 2.4 & 2.9 & 3 & 3.2 & 3.3 & 3.6 & 3.9 & 4.1 & 4.2 & 3.1 \\
\hline Pancreas & 3.3 & 3.3 & 3.7 & 3.9 & 3.8 & 4.1 & 4.2 & 4.2 & 4.4 & 4.6 & 4.5 & 4 \\
\hline $\begin{array}{l}\mathrm{Gl} \\
\text { peritoneum }\end{array}$ & 2.3 & 2.2 & 2.5 & 2.7 & 2.6 & 2.9 & 3 & 3 & 3.1 & 3.2 & 3.2 & 2.8 \\
\hline $\begin{array}{l}\text { Lung, } \\
\text { Bronchus }\end{array}$ & 25.5 & 24.7 & 26.2 & 25.7 & 26.8 & 26.8 & 27.1 & 27.4 & 27.4 & 27.4 & 26.7 & 26.5 \\
\hline $\begin{array}{l}\text { Other } \\
\text { respiratory } \\
\text { tissue }\end{array}$ & 0.3 & 0.3 & 0.4 & 0.3 & 0.3 & 0.4 & 0.4 & 0.4 & 0.4 & 0.4 & 0.3 & 0.4 \\
\hline Bone tissue & 0.9 & 0.9 & 1.1 & 1.2 & 1 & 1.2 & 1.1 & 1.2 & 1.2 & 1.3 & 1.2 & 1.1 \\
\hline $\begin{array}{l}\text { Skin, } \\
\text { Melanomas }\end{array}$ & 3 & 3.1 & 3.6 & 3.9 & 4.3 & 4.8 & 5 & 5.1 & 5.4 & 5.8 & 6.2 & 4.6 \\
\hline $\begin{array}{l}\text { Skin, non- } \\
\text { epithelial }\end{array}$ & 5.6 & 5.9 & 7 & 7.8 & 9.9 & 11 & 11.6 & 12.6 & 13.6 & 15.1 & 16.2 & 10.6 \\
\hline Breast & 28.6 & 28.1 & 29.9 & 30.3 & 32.5 & 33.2 & 34.7 & 35 & 34.6 & 34.4 & 34.1 & 32.3 \\
\hline Uterus & 5.3 & 5 & 5.3 & 5.5 & 5.9 & 5.9 & 6.2 & 6.4 & 6.3 & 6.4 & 6.5 & 5.9 \\
\hline Cervix & 2.5 & 2.5 & 2.7 & 2.7 & 3.1 & 3.2 & 3.2 & 3.3 & 3.3 & 3.4 & 3.4 & 3 \\
\hline Ovary & 4.4 & 4.1 & 4.5 & 4.6 & 4.6 & 4.7 & 4.6 & 4.7 & 4.8 & 4.8 & 4.7 & 4.6 \\
\hline $\begin{array}{l}\text { Other female } \\
\text { cancers }\end{array}$ & 1.1 & 1 & 1.1 & 1.1 & 1.2 & 1.3 & 1.3 & 1.4 & 1.4 & 1.3 & 1.3 & 1.2 \\
\hline Prostate & 25.1 & 25.9 & 27.8 & 28.5 & 30.4 & 30.1 & 32.3 & 31.4 & 31.1 & 30.9 & 30.7 & 29.5 \\
\hline Testis & 0.3 & 0.4 & 0.4 & 0.4 & 0.5 & 0.5 & 0.6 & 0.6 & 0.6 & 0.7 & 0.7 & 0.5 \\
\hline $\begin{array}{l}\text { Other male } \\
\text { cancers }\end{array}$ & 0.2 & 0.2 & 0.2 & 0.2 & 0.2 & 0.2 & 0.2 & 0.2 & 0.2 & 0.3 & 0.2 & 0.2 \\
\hline Bladder & 8 & 8.2 & 8.7 & 8.8 & 9.5 & 9.7 & 10.3 & 10.4 & 10.5 & 10.7 & 10.6 & 9.6 \\
\hline $\begin{array}{l}\text { Kidney } \\
\text { (Renal) }\end{array}$ & 5.8 & 5.9 & 6.8 & 7.1 & 7.7 & 8 & 8.6 & 8.6 & 8.9 & 9.1 & 9.2 & 7.8 \\
\hline $\begin{array}{l}\text { Other urinary } \\
\text { track }\end{array}$ & 0.4 & 0.4 & 0.4 & 0.5 & 0.5 & 0.5 & 0.5 & 0.5 & 0.5 & 0.6 & 0.7 & 0.5 \\
\hline
\end{tabular}




\begin{tabular}{|c|c|c|c|c|c|c|c|c|c|c|c|c|}
\hline \multirow[t]{2}{*}{ Cancer } & \multicolumn{11}{|l|}{ Year } & \multirow{2}{*}{$\begin{array}{l}\text { 11-year } \\
\text { Average }\end{array}$} \\
\hline & 2005 & 2006 & 2007 & 2008 & 2009 & 2010 & 2011 & 2012 & 2013 & 2014 & 2015 & \\
\hline Brain & 1.1 & 1 & 1.1 & 1.1 & 1.2 & 1.3 & 1.3 & 1.4 & 1.4 & 1.4 & 1.4 & 1.2 \\
\hline Thyroid & 1.9 & 2 & 2.3 & 2.5 & 2.5 & 2.8 & 3 & 3.1 & 3.1 & 3.2 & 3.2 & 2.7 \\
\hline Hodgkin & 0.8 & 0.8 & 0.9 & 0.9 & 0.9 & 0.9 & 1 & 1 & 1 & 1 & 1 & 0.9 \\
\hline Non-Hodgkin & 9.3 & 9.2 & 10.3 & 10.2 & 10.4 & 11 & 11.2 & 11.5 & 11.7 & 11.9 & 11.8 & 10.8 \\
\hline Leukemia & 7.1 & 7.2 & 7.9 & 8.1 & 8.3 & 8.4 & 8.7 & 9.1 & 9.5 & 9.5 & 9.3 & 8.5 \\
\hline $\begin{array}{l}\text { Multiple } \\
\text { myeloma }\end{array}$ & 3.9 & 3.6 & 4 & 4.1 & 4.1 & 4.3 & 4.5 & 4.6 & 4.8 & 4.9 & 4.9 & 4.3 \\
\hline $\begin{array}{l}\text { Other } \\
\text { unspecified }\end{array}$ & 1.8 & 1.8 & 2.1 & 2.3 & 2.4 & 2.9 & 2.9 & 3.1 & 3.3 & 3.5 & 3.4 & 2.7 \\
\hline $\begin{array}{l}\text { Secondary } \\
\text { malignancies }\end{array}$ & 41.1 & 38.8 & 43 & 41.5 & 40.9 & 42.7 & 41.2 & 42 & 42.2 & 42.6 & 40.9 & 41.5 \\
\hline $\begin{array}{l}\text { Neoplasms } \\
\text { unspecified }\end{array}$ & 8.1 & 8.5 & 10.6 & 11.1 & 11.9 & 12.1 & 12.7 & 12.8 & 12.9 & 13.4 & 13.5 & 11.6 \\
\hline
\end{tabular}

Table 3 demonstrates the multivariate logistic regression of association between all cancers (1st diagnosis or reason of admission, 2nd -30th diagnoses or comorbidities, and 1st -30th diagnoses or all) and diabetes (uncomplicated, complicated, and both) adjusted by age, sex, race, smoking, alcohol, and obesity in hospitalized patients in the United States from 2005-2015. This analysis revealed that diabetes, including both complicated and uncomplicated, as a 1st 30th diagnosis had a protective role for 33 selected cancers excluding pancreatic cancer (OR: 1.19) and liver and intrahepatic cancer (OR: 1.41). Multivariate adjusted analysis also showed that uncomplicated and complicated diabetes had a slightly protective role (OR>.90) for some cancers including uterine cancer, kidney cancer, GI peritoneum cancer, bladder cancer, and other male-specific cancers. These associations are detailed in Table 3. For more information, see supplement 2. 
Table 3

Summary association (Odds Ratio) from multivariate logistic regression between diabetes and cancers (as 1st or principal diagnosis, as 2 nd to 30 th diagnosis, and diagnosis at anywhere from 1 st to 30 th diagnosis) in hospitalized patients $\geq 50$ years in the United States, 2005-2015

\begin{tabular}{|c|c|c|c|}
\hline \multirow{2}{*}{\begin{tabular}{|l} 
Diabetes \\
Type of \\
diagnosis
\end{tabular}} & \multicolumn{3}{|c|}{ Multivariate analysis } \\
\hline & $1 s t$ & 2nd -30th & $\begin{array}{l}\text { All } \\
\text { (1st-30th) }\end{array}$ \\
\hline \multicolumn{4}{|l|}{ Cancer/cancer group } \\
\hline Head and neck & 0.57 & 0.59 & 0.58 \\
\hline Esophagus & 0.58 & 0.66 & 0.65 \\
\hline Stomach & 0.69 & 0.73 & 0.71 \\
\hline Colon & 0.70 & 0.93 & 0.88 \\
\hline Rectum and anus & 0.60 & 0.69 & 0.66 \\
\hline Liver, intrahepatic & 1.07 & 1.20 & 1.19 \\
\hline Pancreas & 1.39 & 1.43 & 1.41 \\
\hline GI peritoneum & 0.70 & 1.06 & 0.94 \\
\hline Lung, Bronchus & 0.64 & 0.75 & 0.72 \\
\hline Other respiratory tissue & 0.57 & 0.63 & 0.61 \\
\hline Bone tissue & 0.54 & 0.61 & 0.58 \\
\hline Skin, Melanomas & 0.60 & 0.73 & 0.72 \\
\hline Skin, non-epithelial & 0.68 & 0.79 & 0.78 \\
\hline Breast & 0.54 & 0.89 & 0.85 \\
\hline Uterus & 0.69 & 1.01 & 0.92 \\
\hline Cervix & 0.49 & 0.80 & 0.75 \\
\hline Ovary & 0.46 & 0.65 & 0.61 \\
\hline Other female cancers & 0.72 & 0.90 & 0.86 \\
\hline Prostate & 0.37 & 0.83 & 0.74 \\
\hline Testis & 0.46 & 0.82 & 0.81 \\
\hline Other male cancers & 0.83 & 0.95 & 0.93 \\
\hline Bladder & 0.73 & 0.95 & 0.91 \\
\hline Kidney (Renal) & 0.78 & 1.02 & 0.96 \\
\hline Other urinary track & 0.68 & 0.81 & 0.77 \\
\hline Brain & 0.66 & 0.70 & 0.70 \\
\hline Thyroid & 0.60 & 0.87 & 0.80 \\
\hline Gray cells indicate sign & $t a s$ & jation. & \\
\hline
\end{tabular}




\begin{tabular}{|llll|}
\hline Diabetes & \multicolumn{3}{l|}{ Multivariate analysis } \\
\hline Hodgkin & & & \\
\hline Non-Hodgkin & 0.68 & 0.81 & 0.80 \\
\hline Leukemia & 0.69 & 0.78 & 0.77 \\
\hline Multiple myeloma & 0.66 & 0.85 & 0.82 \\
\hline Other unspecified & 0.59 & 0.77 & 0.74 \\
\hline Secondary malignancies & 0.63 & 0.68 & 0.67 \\
\hline Neoplasms unspecified & 0.72 & 0.90 & 0.87 \\
\hline Gray cells indicate significant association. & \\
\hline
\end{tabular}

Figure 2 exhibits the adjusted Odds Ratios from multivariate logistic regression analysis. This analysis also shows that diabetes, including uncomplicated and complicated, had a protective effect for all cancers except for pancreatic cancer and liver and intrahepatic cancer.

\section{Discussion}

In this survey, we examined the relationship between diabetes and risk of selected cancer in 44,262,443 discharges with $13,048,961$ diabetes patients and 11,752,871 cases of 33 different cancers between $2005-15$. Our analysis shows that diabetes might play a role in decreasing the risk of most selected cancers except for pancreatic cancer, and liver and intrahepatic cancers. These findings are based upon a number of adjusted multivariate logistic regression analyses. To the best of our knowledge, this is the first inpatient survey to investigate the relationship between diabetes and selected cancers in a large population.

Although some studies have shown that there is a mechanism for the link between diabetes and cancer in many sitespecific cancers, there is widespread debate regarding the limitations of these studies for conclusive interpretation of the outcome ${ }^{3-6}$. Enormous progress has been made in the understanding of diabetes and cancer etiology. A Mendelian randomization study revealed that there is little evidence in the Japanese population to support the genetic role of type 2 diabetes in cancer risk ${ }^{4}$. Novel biomarkers of cancer found in tumor tissues and fluids such as DNA, mRNA, transcription factors, cell surface receptors, secreted proteins, and small metabolites, are being examined to determine cancer risk in prediabetic and non-diabetic individuals ${ }^{5}$. Some epidemiology studies report an increased incidence of cancers in some diseases including obesity, metabolic syndrome, polycystic ovary syndrome, insulin-resistant states, and diabetes ${ }^{10}$. The common mechanism linking these diseases to a cancer could be related to hyperinsulinemia, hyperglycemia, inflammation and oxidative stress ${ }^{5}$. Furthermore, oncogenic effects of some anti-hyperglycemic drugs is an important potential mechanism that might effect cancer progression ${ }^{11}$. Several studies have found that anti-hyperglycemic drugs have both a positive and negative effect on cancer progression. Based on the American Association of Clinical Endocrinologists and the American College of Endocrinology (AACE/ACE) consensus statement, metformin is thought to play a protective role in cancer development, while exogenous insulin use appears to be associated with an increased risk of cancer. The effect of newer diabetes medications on cancer progression remains uncertain ${ }^{9}$. While medication for the treatment of diabetes may affect cancer risk, the totality of evidence is not conclusive and future research is required. In addition, specific common risk factors for each type of cancer in the diabetic population have not yet been thoroughly established. In this regard, more research is needed to identify these common risk factors as well as a detailed mechanism to explain the 
relationship between cancer risk and diabetes. In summary, there are likely complex mechanisms that link diabetes and certain cancers. Whether diabetes leads to cancer or cancer induces diabetes is still unclear. More research needs to be conducted, specifically to obtain the etiology behind diabetes and cancer.

This study showed that patients with diabetes were more likely to have pancreatic and hepatic and intrahepatic cancers compared to non-diabetic patients. This finding broadly supports the work of other studies in this area linking diabetes with pancreatic and hepatic and intrahepatic cancer ${ }^{21-24}$. A population-based research study also found that within 3 years of first meeting the diabetes criteria, approximately $1 \%$ of people with diabetes at age 50 will be diagnosed with pancreatic cancer ${ }^{25}$. In addition, among individuals in five large prospective cohorts, the risk of pancreatic cancer among diabetic patients increased and was independently associated with increased circulating peripheral insulin resistance markers ${ }^{26-29}$. In a 2019 study, a nationwide cohort showed that metformin did not promote a survival benefit in individuals with pancreatic cancer-related diabetes ${ }^{30}$. Furthermore, a population-based cohort study found that for patients with diabetes, comorbidity with cirrhosis and/or hepatitis was associated with a high risk of developing increased risk of hepatocellular carcinoma ${ }^{31,32}$. Notably, metformin therapy was associated with a reduced risk of hepatic and intrahepatic cancer in diabetic patients ${ }^{33}$. Further high-quality studies are needed to explain the mechanisms behind this relationship.

This study indicated that there was mild or no significant relationship between diabetes and kidney cancer, GI peritoneum cancers, uterine cancer, or bladder cancer. However, the findings of the current study do not completely support previous research. A recent Meta-analysis revealed that there was a positive association between diabetes and the risk of kidney cancer but points out that future research should attempt to determine whether this association is causative ${ }^{29}$. In addition, few studies have been carried out that show a strong relationship between diabetes and GI peritoneum cancers ${ }^{34}$. Additionally, the results of the current study on uterine cancer do not support the preceding studies. Analysis of two related statistical databases in England found significantly high odds ratios for uterine cancers (OR:1.52;1.04-2.16) in patients with diabetes ${ }^{35}$. One explanation that could justify the null finding found in our survey is the relatively low frequency of these cancers in general ${ }^{36}$. The National Health Insurance Study from Taiwan found that patients with diabetes are at increased risk of bladder cancer with a complex relationship scenario ${ }^{37}$. In the United States, a cohort study showed that the incidence of bladder cancer increased with anti-hyperglycemic medication (pioglitazone) in diabetics aged $\geq 65$ years, but not in incident cohorts ${ }^{38}$. A meta-analysis showed a modest positive association between the incidence of bladder cancer and type 1 diabetes, which is not statistically significant ${ }^{39}$. In summary, there is a need for more extensive studies of the mentioned cancers to determine a positive, null, or negative relationship with diabetes.

The present study revealed that diabetes had a protective role for the remaining selected cancers, including prostate, lung and bronchus, colon, and rectal cancers. These results are partially consistent with the literature for these selected cancers. The results of the current study is consistent with the Cai $\mathrm{H}$ study, in which meta-analysis involving 11 cohort studies showed that diabetes is linked to a poor prognosis among those with prostate cancer ${ }^{40}$. The details of this association of diabetes with the incidence and prognosis of prostate cancer is still uncertain. However, there is a possible mechanism for the influence of medication, especially Metformin ${ }^{41,42}$ and genetic factors ${ }^{43}$. Furthermore, one study showed that diabetes in patients with non-small cell lung cancer is associated with a lower risk of metastasis ${ }^{14}$. In contrast to previous studies, our current analysis showed no evidence that diabetes might increase breast, endometrial, kidney, colon, and rectal cancers. In addition, the findings of the current study do not support previous research regarding colon and rectum cancer.

The association between diabetes and the incidence and progression of cancer is not fully understood, but some associated variables, such as duration of disease, weight, etc., may have an influence requiring careful consideration. Furthermore, in a case-control study that was published in 2016, the duration of diabetes in the diabetic and non- diabetic subjects was not significantly different in relation to the progression to cancer ${ }^{44}$, but more research is needed. In addition, 
sedentary lifestyle, obesity and unhealthy diet are common risk factors for diabetes and cancer. Compared to normal weight individuals, obese patients with poorly controlled insulin-treated type 2 diabetes mellitus are prone to malignancies, particularly breast cancer in women and colorectal cancer in men ${ }^{44}$. The patient's lifestyle, including diet and physical activity, may change following diagnosis of diabetes via consultation with health care providers. This can increase the complexity of the interaction between diabetes and certain cancers and may help explain the relationship between diabetes and cancer risk.

The strengths of our study include vast nationwide hospital-based data, large sample size, and precise and accurately defined exposures, outcomes, and demographics by ICD-9-CM. In addition, important factors such as sex, age, race, obesity, cigarette smoking and alcohol consumption were extracted to conduct multivariate analysis. Due to the large sample size, this study is very robust. However, any small association may be statistically significant but may not be clinically valuable. Nonetheless, a number of limitations need to be addressed. First, we were unable to assess the details of the risk factors, genetic factors, and some confounding effects. Second, in the HCUP-NIS database, we cannot verify the time sequence between cancers and diabetes or other confounders. A standard prospective cohort study is needed to find a precise and accurate association. Third, while we included confounding factors such as age, sex, race, smoking, alcohol, and obesity in multivariate logistic regression, there is a lack of other confounding factors in the database, such as occupational exposures, environmental exposures, and medication of diabetic patients.

\section{Conclusion}

Assumption of the relation of diabetes and cancers could be considered due to common risk factors, change in lifestyle after diabetes diagnosis, and probable positive or negative molecular or biological mechanisms linking diabetes and cancers. This study with a large amount of individual data presents new information regarding the likelihood of a protective role for diabetes in some cancers. The multivariate logistic regression provides evidence that diabetes has a protective role for all cancers except for pancreatic, and liver and intrahepatic cancer. These results must be interpreted with caution due to the previously mentioned limitations of this study. Continued efforts are needed to provide a detailed mechanism linking diabetes and certain cancers.

\section{Declarations}

\section{Funding:}

None

\section{Conflict of Interest:}

Noconflict

\section{Acknowledgment:}

None

\section{References}

1. Association, A. D. Economic costs of diabetes in the US in 2017. Diabetes care, 41 (5), 917-928 (2018).

2. Society, A. C. Cancer Facts \& Figures 2019

3. Giovannucci, E. et al. Diabetes and cancer: a consensus report. CA: a cancer journal for clinicians, 60 (4), $207-221$ (2010).

4. Goto, A. et al. Diabetes and cancer risk: A Mendelian randomization study.International journal of cancer. 2019. 
5. Abudawood, M. Diabetes and cancer: A comprehensive review. Journal of Research in Medical Sciences, 24 (1), 9494 (2019).

6. Harding, J. L., Shaw, J. E., Peeters, A., Cartensen, B. \& Magliano, D. J. Cancer risk among people with type 1 and type 2 diabetes: disentangling true associations, detection bias, and reverse causation. Diabetes care, 38 (2), 264-270 (2015).

7. Vigneri, P., Frasca, F., Sciacca, L., Pandini, G. \& Vigneri, R. Diabetes and cancer. Endocrine-related cancer, 16 (4), $1103-$ 1123 (2009).

8. Collins, K. K. The diabetes-cancer link. Diabetes Spectrum, 27 (4), 276-280 (2014).

9. Handelsman, Y. et al. Diabetes and cancer-an AACE/ACE consensus statement. Endocr. Pract, 19 (4), 675-693 (2013).

10. Cohen, D. H., LeRoith, D. \& Obesity type 2 diabetes, and cancer: the insulin and IGF connection. Endocrine-related cancer, 19 (5), F27-F45 (2012).

11. Gallagher, E. J. \& LeRoith, D. Diabetes, cancer, and metformin: connections of metabolism and cell proliferation. Annals of the New York Academy of Sciences, 1243 (1), 54-68 (2011).

12. Cannata, D., Fierz, Y., Vijayakumar, A. \& LeRoith, D. Type 2 diabetes and cancer: what is the connection? Mount Sinai Journal of Medicine: A Journal of Translational and Personalized Medicine. A Journal of Translational and Personalized Medicine, 77 (2), 197-213 (2010).

13. Dankner, R. et al. A historical cohort study on glycemic-control and cancer-risk among patients with diabetes. Cancer epidemiology, 57, 104-109 (2018).

14. Hanbali, A., Al-Khasawneh, K., Cole-Johnson, C., Divine, G. \& Ali, H. Protective effect of diabetes against metastasis in patients with non-small cell lung cancer. Archives of internal medicine, 167 (5), 513-513 (2007).

15. Dartois, L., Fagherazzi, G., Boutron-Ruault, M-C., Mesrine, S. \& Clavel-Chapelon, F. Association between five lifestyle habits and cancer risk: results from the E3N cohort. Cancer Prevention Research, 7 (5), 516-525 (2014).

16. Feldman, A. L. et al. Change in lifestyle behaviors and diabetes risk: evidence from a population-based cohort study with 10 year follow-up. international journal of behavioral nutrition and physical activity, 14 (1), 39 (2017).

17. Peña-Longobardo, L. et al. Is quality of life different between diabetic and non-diabetic people? The importance of cardiovascular risks. PloS one, 12 (12), e0189505 (2017).

18. Juntarawijit, C. \& Juntarawijit, Y. Comparison of sleep and health behaviors among diabetic patients and nondiabetics in Phitsanulok, Thailand: a cross-sectional study. F1000Research, 8 (1030), 1030 (2019).

19. Koopman, R. J., Mainous, A. G., Diaz, V. A. \& Geesey, M. E. Changes in age at diagnosis of type 2 diabetes mellitus in the United States, 1988 to 2000. The Annals of Family Medicine, 3 (1), 60-63 (2005).

20. White, M. C. et al. Age and cancer risk: a potentially modifiable relationship. American journal of preventive medicine, 46 (3), S7-S15 (2014).

21. Pizzato, M., Turati, F., Rosato, V. \& La Vecchia, C. Exploring the link between diabetes and pancreatic cancer. Expert review of anticancer therapy, 19 (8), 681-687 (2019).

22. Risch, H. A. Diabetes and pancreatic cancer: both cause and effect (Oxford University Press, 2019).

23. Sharma, A. et al. Model to determine risk of pancreatic cancer in patients with new-onset diabetes., 155 (3), $730-739$ (2018). e3

24. Setiawan, V. W. et al. Pancreatic cancer following incident diabetes in African Americans and Latinos: the multiethnic cohort. JNCl: Journal of the National Cancer Institute, 111 (1), 27-33 (2019).

25. Chari, S. T. et al. Probability of pancreatic cancer following diabetes: a population-based study., 129 (2), 504-511 (2005). 
26. Wolpin, B. M. et al. Hyperglycemia, insulin resistance, impaired pancreatic $\beta$-cell function, and risk of pancreatic cancer. Journal of the National Cancer Institute, 105 (14), 1027-1035 (2013).

27. Dankner, R. et al. Time-dependent risk of cancer after a diabetes diagnosis in a cohort of 2.3 million adults. American journal of epidemiology, 183 (12), 1098-1106 (2016).

28. Liao, K. F., Lai, S. W., Li, C. I. \& Chen, W. C. Diabetes mellitus correlates with increased risk of pancreatic cancer: a population-based cohort study in Taiwan. Journal of gastroenterology and hepatology, 27 (4), 709-713 (2012).

29. Larsson, S. \& Wolk, A. Diabetes mellitus and incidence of kidney cancer: a meta-analysis of cohort studies., 54 (5), 1013-1018 (2011).

30. Cho, J., Scragg, R., Pandol, S. J., Goodarzi, M. O. \& Petrov, M. S. Antidiabetic Medications and Mortality Risk in Individuals With Pancreatic Cancer-Related Diabetes and Postpancreatitis Diabetes: A Nationwide Cohort Study.Diabetes care. 2019:dc190145.

31. Lai, S-W. et al. Risk of hepatocellular carcinoma in diabetic patients and risk reduction associated with anti-diabetic therapy: a population-based cohort study. The American journal of gastroenterology, 107 (1), 46 (2012).

32. El-serag, H. B., Tran, T. \& Everhart, J. E. Diabetes increases the risk of chronic liver disease and hepatocellular carcinoma., 126 (2), 460-468 (2004).

33. Zhang, H., Gao, C., Fang, L., Zhao, H-C. \& Yao, S-K. Metformin and reduced risk of hepatocellular carcinoma in diabetic patients: a meta-analysis. Scandinavian journal of gastroenterology, 48 (1), 78-87 (2013).

34. Bakhru, A., Buckanovich, R. J. \& Griggs, J. J. The impact of diabetes on survival in women with ovarian cancer. Gynecologic oncology, 121 (1), 106-111 (2011).

35. Wotton, C., Yeates, D. \& Goldacre, M. Cancer in patients admitted to hospital with diabetes mellitus aged 30 years and over: record linkage studies., 54 (3), 527-534 (2011).

36. Siegel, R. L., Miller, K. D., Jemal, A. \& Cancer statistics 2019. CA: a cancer journal for clinicians. 2019;69(1):7-34.

37. Tseng, C-H. Diabetes and risk of bladder cancer: a study using the National Health Insurance database in Taiwan., 54 (8), 2009-2015 (2011).

38. Mackenzie, T. A., Zaha, R., Smith, J., Karagas, M. R. \& Morden, N. E. Diabetes pharmacotherapies and bladder cancer: a medicare epidemiologic study. Diabetes Therapy, 7 (1), 61-73 (2016).

39. Oskoui, H. B. et al. 1685-P: Type 1 Diabetes Mellitus and Incident Bladder Cancer: A Systematic Review and Metaanalysis (Am Diabetes Assoc, 2019).

40. Cai, H., Xu, Z., Xu, T., Yu, B. \& Zou, Q. Diabetes mellitus is associated with elevated risk of mortality amongst patients with prostate cancer: a meta-analysis of 11 cohort studies. Diabetes/metabolism research and reviews, 31 (4), 336343 (2015).

41. Zingales, V. et al. Metformin: a bridge between diabetes and prostate cancer. Frontiers in oncology, 7, 243 (2017).

42. Häggström, C. et al. Prospective study of Type 2 diabetes mellitus, anti-diabetic drugs and risk of prostate cancer. International journal of cancer, 140 (3), 611-617 (2017).

43. Frayling, T., Colhoun, H. \& Florez, J. A genetic link between type 2 diabetes and prostate cancer., 51 (10), 1757-1760 (2008).

44. Dąbrowski, M., Szymańska-Garbacz, E., Miszczyszyn, Z., Dereziński, T. \& Czupryniak, L. Risk factors for cancer development in type 2 diabetes: A retrospective case-control study. BMC cancer, 16 (1), 785 (2016).

\section{Supplements}

Supplements 1 and 2 are not available with this submission.

\section{Figures}

Page 14/16 


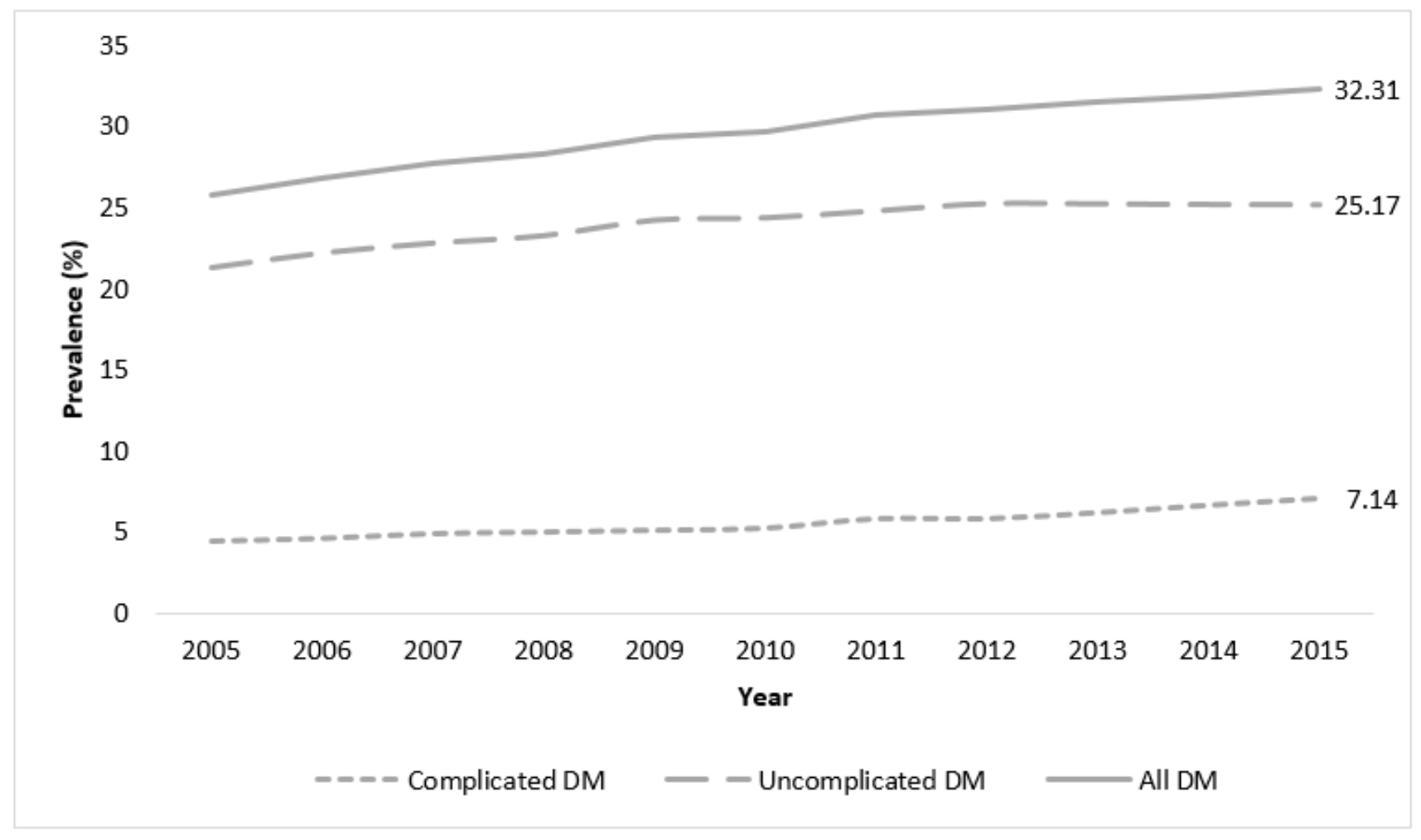

Figure 1

Trend of diabetes prevalence among hospitalized patients $\geq 50$ years in the United States, 2005-15

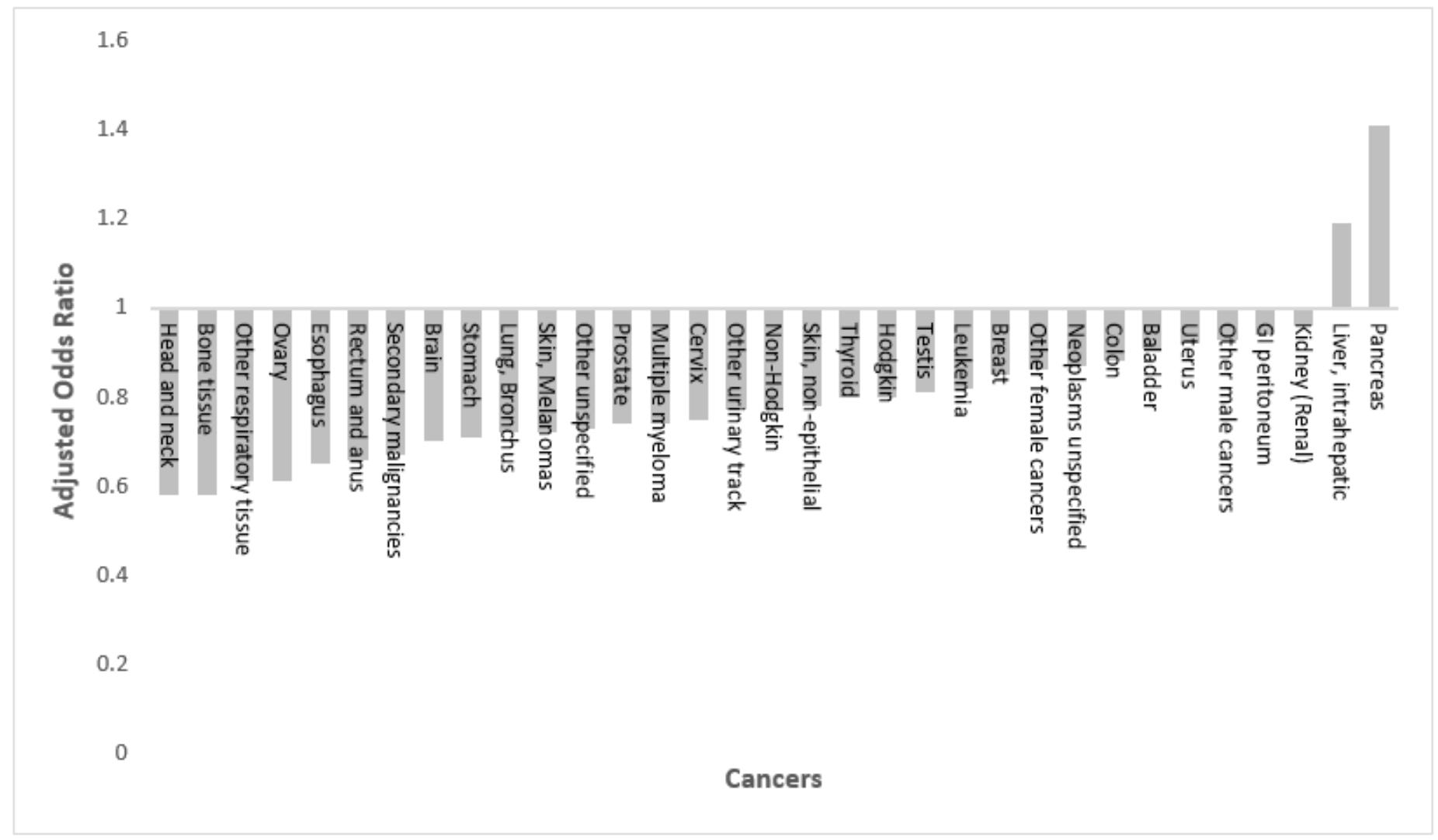

Figure 2 
Brief multivariate logistic regression analysis (adjusted Odds ratio) between diabetes (both uncomplicated and complicated) and selected cancers (at 1st to 30th diagnosis) among hospitalized inpatients $\geq 50$ years in the United States, 2005-15. 